ИЗВЕСТИЯ АКАДЕМИИ НАУК ЭСТОНСКОЙ ССР. ТОМ 27 ХИМИЯ. 1978, № 4

\title{
ИНФРАКРАСНЫЕ СПЕКТРЫ ЦИКЛОПЕНТЕНОВЫХ УГЛЕВОДОРОДОВ
}

Инфракрасные спектры циклопентеновых углеводородов, изучены весьма недостаточно. Так, в литературе описаны опектры лишь 1-, 3-, 4-метили 1-, 3-, 4-этил-1-циклопентенов. Эти данные не позволяют проводить надежную идентификацию высших членов этого гомологического ряда. В настоящей работе оистематически исследовались 1- и 3-н-алкил-1циклопентены до $\mathrm{C}_{13}$. С целью выяснения влияния структуры боковой цепи на характер ИК-спектра были изучены 1- и 3-замещенные циклопентены с изоалкильными $\left(\mathrm{C}_{3}-\mathrm{C}_{5}\right)$, аллильным, фенильным и бензильным заместителями.

В спектрах исследованных соединений (таблица) имеются полосы, соответствующие антисимметричным $\left(v_{\mathrm{as}}\right)$ и симметричным $\left(v_{\mathrm{s}}\right)$ валентным колебаниям метильных и метиленовых групп: 2967-2950 $\left(v_{\text {as }} \mathrm{CH}_{3}\right), 2938-2927\left(v_{\text {as }} \mathrm{CH}_{2}\right), 2876-2870\left(v_{\mathrm{s}} \mathrm{CH}_{3}\right)$ и $2858-2848 \cdot \mathrm{cm}^{-1}$ $\left(v_{\mathrm{s}} \mathrm{CH}_{2}\right)$. Колебания этих значений - не более, чем $\pm 9 \mathrm{~cm}^{-1}$.

Интенсивные полосы поглощения при 1468-1462 $\mathrm{cm}^{-1}$ обусловлены антисимметричными $\left(\delta_{\mathrm{as}}\right)$ деформационными колебаниями метильных и метиленовых групп и при $1384-1373 \mathrm{~cm}^{-1}-$ симметричными $\left(\delta_{\mathrm{s}}\right)$ деформационными колебаниями метильных групп.

Изопропильная группа дает очень четкое расщепление симметричных деформационных колебаний метильной пруппы [ $\left.{ }^{1-5}\right]$. Так, при наличии в молекуле изопропильной группы в спектре имеются полосы при

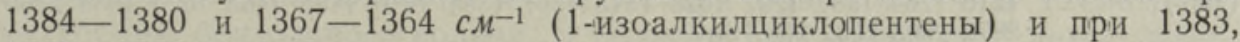

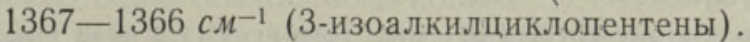

Для группы $\left(\mathrm{CH}_{3}\right)_{2} \mathrm{CH}$ характерно также поглощение при $1178-1168$ и 1208-1206 $\mathrm{cm}^{-1}$ (1-изоалкилциклопентены) и 1180 -1170 и 1210 $1205 \mathrm{~cm}^{-1}$ (3-изоалкилциклопентены).

Наличие двойной связи подтверждается появлением полос поглощения в областях 1650 и выше $3000 \mathrm{~cm}^{-1}$.

Аналогично тризамещенным этиленам $\left(\mathrm{RHC}=\mathrm{CR}^{\prime} \mathrm{R}^{\prime \prime}\right)$ 1-алкил-1циклопентены имеют полосы поглощения, соответствующие валентным колебаниям $v=\mathrm{CH}$ циклопентенового кольца, при $3047-3044 \mathrm{~cm}^{-1}$ и 3-алкил-1-циклопентены (подобно дизамещенным этиленам RHC $=\mathrm{CHR}^{\prime}$, цис-конфигурация) при 3058-3056 $\mathrm{cm}^{-1}$, а 1- и 3-аллилциклопентены, соответственно, - при 3050 и 3058 c $M^{-1}$ (таблица).

Частоты поглощения при $3082-3080$ и $3008,3000 \mathrm{~cm}^{-1}$ в аллилциклопентенах соответствуют валентным колебаниям $=\mathrm{CH}$ винильной группы заместителя. Таким образом, наличие частот поглощения при 3058,3050 и $3082-3080 \mathrm{~cm}^{-1}$ указывает на присутствие двух различных типов двойной связи в молекулах аллилциклопентенов. 
Частоты поглощения 1- и 3-замещенных циклопентенов $\mathrm{C}_{6}-\mathrm{C}_{13}$

\begin{tabular}{c|c}
\hline $\begin{array}{l}\text { Заместитель и } \\
\text { его положение } \\
(\text { чистота, \%) }\end{array}$ & Частота, $c \mu^{-1}$ \\
\hline 1 & 2 \\
\hline
\end{tabular}

1-Этил

$(99,9)$

1-Аллил $(99,9)$

1-н-Пропил $(99,5)$

1-н-Бутил $(98,0)$

$1-$-Пентил $(99,0)$

1-н-Гексил $(99,0)$

1-Фенил $(99,2)$

1-Бензил $(95,0)$

1-н-Октил $(95,0)$

1-Изопропил $(99,9)$

1-Изобутил $(99,7)$

1-Изопентил $(99,8)$

3-Метил $(99,9)$

3-Этил $(99,9)$

3-Аллил $(99,9)$

3-н-Пропил $(99,7)$

3-н-Бутил $(99,9)$

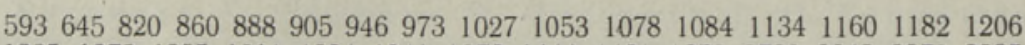
$\begin{array}{llllllllllllll}1235 & 1273 & 1295 & 1311 & 1324 & 1341 & 1376 & 1444 & 1461 & 1653 & 2730 & 2848 & 2870 & 2895\end{array}$ 29382957296730463055

$\begin{array}{llllllllllllllll}634 & 714 & 751 & 805 & 819 & 913 & 962 & 996 & 1027 & 1038 & 1067 & 1093 & 1130 & 1150 & 1176 & 1205\end{array}$ $\begin{array}{llllllllllllll}1225 & 1263 & 1285 & 1297 & 1340 & 1350 & 1412 & 1428 & 1443 & 1468 & 1550 & 1560 & 1646 & 1716\end{array}$ 17271831284928702897293029542980300830503082

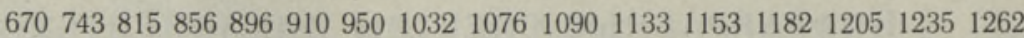
$\begin{array}{llllllllllllll}1280 & 1295 & 1317 & 1330 & 1378 & 1440 & 1455 & 1463 & 1621 & 1652 & 2736 & 2847 & 2873 & 2900\end{array}$ 293329583047

$\begin{array}{llllllllllllllll}605 & 667 & 730 & 746 & 820 & 873 & 900 & 930 & 953 & 1034 & 1084 & 1101 & 1132 & 1153 & 1180 & 1207\end{array}$ $\begin{array}{llllllllllllll}1234 & 1248 & 1262 & 1295 & 1315 & 1340 & 1377 & 1445 & 1453 & 1465 & 1627 & 1654 & 2590 & 2670\end{array}$ 27352848286028752900293029583046

$\begin{array}{llllllllllllllll}667 & 730 & 815 & 844 & 890 & 904 & 943 & 967 & 982 & 1037 & 1075 & 1090 & 1105 & 1132 & 1153 & 1185\end{array}$ $\begin{array}{llllllllllllll}1208 & 1258 & 1275 & 1294 & 1317 & 1338 & 1377 & 1450 & 1465 & 1623 & 1653 & 2670 & 2733 & 2851\end{array}$ 286028742900292929583045

$\begin{array}{llllllllllllllll}670 & 726 & 804 & 818 & 860 & 893 & 908 & 947 & 968 & 1000 & 1025 & 1038 & 1077 & 1093 & 1110 & 1131\end{array}$ $\begin{array}{llllllllllllll}1151 & 1181 & 1208 & 1263 & 1275 & 1295 & 1316 & 1340 & 1377 & 1445 & 1455 & 1465 & 1654 & 2668\end{array}$ 2733285528732900292929573045

$\begin{array}{llllllllllllllll}632 & 670 & 695 & 815 & 839 & 890 & 908 & 959 & 980 & 1003 & 1039 & 1074 & 1104 & 1133 & 1158 & 1184\end{array}$ $\begin{array}{llllllllllllll}1210 & 1247 & 1267 & 1296 & 1327 & 1342 & 1381 & 1447 & 1496 & 1576 & 1600 & 1628 & 1665 & 1695\end{array}$ $\begin{array}{llllllllllllll}1708 & 1730 & 1747 & 1778 & 1800 & 1818 & 1857 & 1874 & 1890 & 2847 & 2869 & 2895 & 2932 & 2955\end{array}$ 302730333050305830823105

$\begin{array}{llllllllllllllll}700 & 719 & 740 & 758 & 812 & 830 & 890 & 915 & 927 & 967 & 1005 & 1032 & 1039 & 1110 & 1128 & 1156\end{array}$ $\begin{array}{llllllllllllll}1182 & 1208 & 1258 & 1296 & 1325 & 1337 & 1343 & 1358 & 1385 & 1435 & 1445 & 1455 & 1470 & 1497\end{array}$ $\begin{array}{llllllllllllll}1547 & 1588 & 1606 & 1653 & 1718 & 2850 & 2870 & 2899 & 2930 & 2954 & 3006 & 3032 & 3067 & 3089\end{array}$ 3110

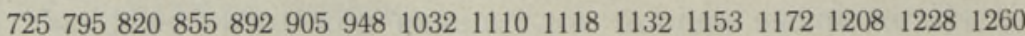
$\begin{array}{llllllllllllll}1297 & 1317 & 1342 & 1355 & 1370 & 1378 & 1445 & 1455 & 1467 & 1654 & 1720 & 1740 & 2858 & 2876\end{array}$ 2900293029603047

$\begin{array}{llllllllllllllll}612 & 698 & 767 & 810 & 891 & 909 & 920 & 948 & 960 & 1018 & 1035 & 1071 & 1100 & 1118 & 1133 & 1178\end{array}$ $\begin{array}{llllllllllllll}1208 & 1251 & 1296 & 1308 & 1343 & 1364 & 1380 & 1450 & 1468 & 1649 & 2582 & 2654 & 2723 & 2754\end{array}$ 2849287228952932296230453057

$\begin{array}{lllllllllllllll}789 & 830 & 855 & 896 & 910 & 924 & 952 & 1036 & 1090 & 1105 & 1113 & 1133 & 1155 & 1168 & 1206\end{array}$

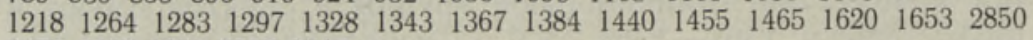
28722903293229573047

$\begin{array}{llllllllllllllll}763 & 797 & 815 & 862 & 888 & 903 & 920 & 940 & 953 & 977 & 1038 & 1094 & 1110 & 1118 & 1132 & 1168\end{array}$

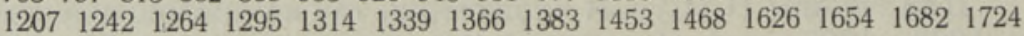
27222732276328502871293229573044

$\begin{array}{lllllllllllllll}720 & 847 & 896 & 937 & 958 & 983 & 1053 & 1081 & 1095 & 1119 & 1180 & 1198 & 1240 & 1280 & 1293\end{array}$

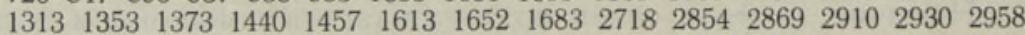
3056

$\begin{array}{lllllllllllllll}718 & 850 & 912 & 936 & 964 & 982 & 1013 & 1028 & 1063 & 1094 & 1172 & 1198 & 1250 & 1262 & 1286\end{array}$

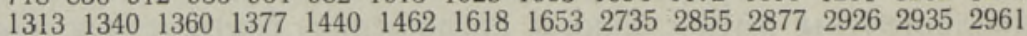
30563220

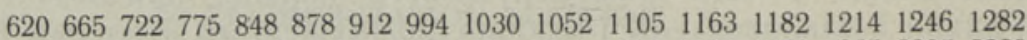

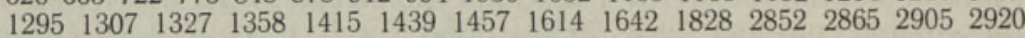
2950298030003058308032183272

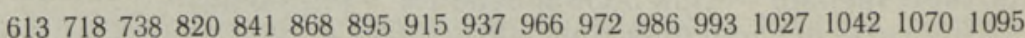

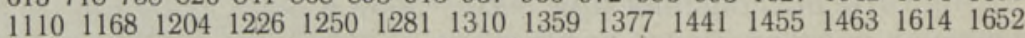
27332850286328742900292829593056

$\begin{array}{llllllllllllllll}613 & 718 & 858 & 894 & 913 & 924 & 960 & 976 & 1034 & 1058 & 1080 & 1098 & 1113 & 1164 & 1180 & 1207\end{array}$

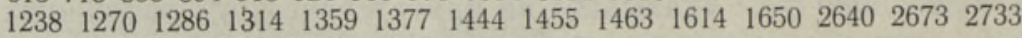
28532875292729583056 
$1 \mid 2$

3-н-Пентил

$(98,7)$

3-н-Гексил

$(99,5)$

3-Фенил

$(99,2)$

3-Изопропил $(99,9)$

3-Изопентил $(99,9)$

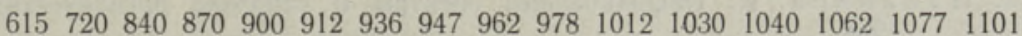

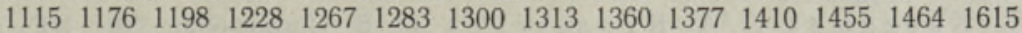
16512720273528542875292629583057

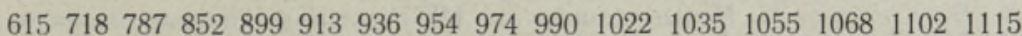

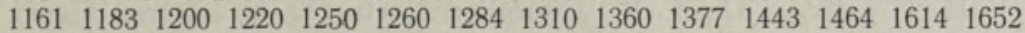
267527202734285628752927295830573212

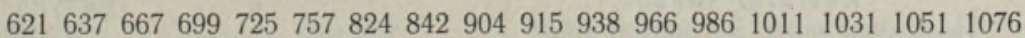
$\begin{array}{llllllllllllllll}1106 & 1145 & 1155 & 1180 & 1204 & 1259 & 1286 & 1297 & 1316 & 1335 & 1353 & 1382 & 1441 & 1452\end{array}$ $\begin{array}{llllllllllllll}1493 & 1545 & 1585 & 1602 & 1660 & 1745 & 1804 & 1870 & 1882 & 1947 & 1960 & 1986 & 2852 & 2866\end{array}$ 29002933294229583004302830593082

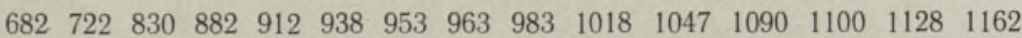
$\begin{array}{lllllllllllllll}1180 & 1205 & 1257 & 1263 & 1288 & 1320 & 1328 & 1336 & 1366 & 1383 & 1440 & 1454 & 1467 & 1614\end{array}$ 1653258026202645272527302762285228742914293529593058

$\begin{array}{llllllllllllllll}615 & 718 & 773 & 813 & 844 & 863 & 912 & 930 & 936 & 974 & 1014 & 1047 & 1067 & 1103 & 1130 & 1170\end{array}$

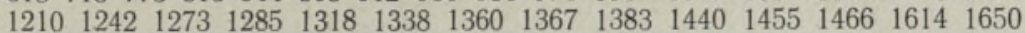
273028522873292529583056

Валентным колебаниям двойной связи $\mathrm{C}=\mathrm{C}$ соответствует полоса поглощения при $1654-1649 \mathrm{~cm}^{-1}-1$-алкил-1-циклопентены, при $1654-$ 1649 и $1614 \mathrm{CM}^{-1}$ - 3-изомеры. В спектре 1-аллил-1-циклопентена имеется сильная полоса поглощения при 1646 и у 3-изомера при $1642 \mathrm{~cm}^{-1}$.

Неплоские деформационные колебания $\delta$ групп $=\mathrm{CH}_{2}$ и $=\mathrm{CH}$ лежат в области $1000-700 \mathrm{~cm}^{-1}$ [5]. Частота поглощения при $1830 \mathrm{~cm}^{-1}$ в ИК-спектрах аллилциклопентенов является, очевидно, обертоном полосы поглощения при $912 \mathrm{~cm}^{-1}(\delta=\mathrm{CH})$.

Известно, что присутствие ароматической группы обнаруживается по полосам поглощения около 3030 и в области $1600-1500$ cм$^{-1}$, а характер замещения определяется по сильному поглощению ниже $900 \mathrm{~cm}^{-1}$. Поглощения в области 2000-1660 $\mathrm{cm}^{-1}$ характерны для различных типов замещения [1-5]. Значит, полоса поглощения при частоте $3032 \mathrm{~cm}^{-1}$ (1-бензил-1-циклопентен) относится к валентным колебаниям ароматической СН-связи ( $v$ CH аром.) и частоты поглощения при 3006, 3065 , $3085 \mathrm{~cm}^{-1}-\mathrm{K}$ колебаниям =CH циклопентенового кольца. Частоты поглощения при 1606, 1585, $1497 \mathrm{~cm}^{-1}$ можно отнести к валентным колебаниям $v \mathrm{C}=\mathrm{C}$ бензольного кольца и при $1453 \mathrm{~cm}^{-1}-\mathrm{K}$ скелетному колебанию бензольного кольца. В области 1200-1000 cm-1 лежат плоские деформационные колебания бензольного кольца. Колебания при частотах $747-737 \mathrm{~cm}^{-1}$ в спектре 1-бензил-1-циклопентена можно отнести к неплоским деформационным колебаниям $\left(\delta \mathrm{C}_{\mathrm{Ar}} \mathrm{H}\right)$.

По приведенным ИК-спектрам можно определить структуру соединения и качественный состав веществ. UR-20.

ИК-спектры снимались в области $3300-590$ c. $^{-1}$ на спектрометре 


\section{ЛИТЕРАТУ Р А}

1. Бе л л а м и Л. Инфракрасные спектры сложных молекул. М., 1963.

2. Наканиси К. Инфракрасные спектры и строение органических молекул. М., 1965.

3. К а зи цын а Л. А., К упле тск а я Н. Б. Применение УФ-, ИК- и ЯМР-спектроскопии в органической химии. М., 1971.

4. Белл а м и Л. Новые данные по ИК-спектрам сложных молекул. М., 1971.

5. Holly, S., Sohar, P. Absorption spectra in the infrared region. Budapest, 1975.

Ннститут химиі

Академии наук Эстонской ССР
Поступила в редакцию 10/XI 1977

Maimu LEHTVEER, Silvia RANG, O. EISEN

\section{TSUKLOPENTEENIDE INFRAPUNASED SPEKTRID}

Artiklis on esitatud 1- ja 3-asendatud tsüklopenteenide infrapunaste spektrite uurimise $\mathrm{ja}$ interpreteerimise tulemused. Asendajatena on kasutatud $n$-alküül- $\left(\mathrm{C}_{1}-\mathrm{C}_{8}\right)$, isoalküül$\left(C_{3}-C_{5}\right)$, allüül-, fenüül- ja bensüülrühmi.

Maimu LEHTVEER, Silvia RANG, O, EISEN

\section{INFRARED SPECTRA OF CYCLOPENTENES}

The infrared spectra of $\mathrm{C}_{6}-\mathrm{C}_{13} \quad 1$ - and 3 -substituted cyclopentenes with $\mathrm{C}_{1}-\mathrm{C}_{8}$ $n$-alkyl, $\mathrm{C}_{3}-\mathrm{C}_{5}$ isoalkyl, allyl, phenyl and benzyl substituents are investigated and analyzed. 